\title{
Inclusion or Exclusion? Critical Needs of Hearing Impaired Learners during an English Reading Comprehension Lesson
}

\author{
Agness Chimangeni Chaliwa Hara \\ Department of Language, Cultural and Creative Studies, Mzuzu University, Malawi \\ Email: hara.a@mzuni.ac.mw
}

\begin{abstract}
Drawing on the social inclusion theoretical model, this study examines critical needs of hearing impaired learners during an English reading comprehension lesson. Some of the challenges that hearing impaired learners experience arise due to their exclusion from activities, participation and access. The study utilised qualitative approaches through semi-structured interviews. A total of twenty-six participants from three secondary schools located in the northern region of Malawi participated in this study as follows: seven regular teachers, two specialist teachers, two resource persons and fifteen hearing impaired learners. The results reveal that most hearing impaired learners do not manage to attain all reading comprehension objectives. Although teachers use a combination of strategies during a reading comprehension lesson, they do not utilise strategies that promote higher-order cognitive thinking skills. Finally, the results reveal that hearing impaired learners encounter several challenges some of which may be avoided if teachers embrace inclusive practices. The results have implications for stakeholders, teachers and researchers as follows: there is a need to improve the inclusive system of education by providing in-service training for teachers and employing competent specialist teachers and resource persons to facilitate the learning of hearing impaired learners. There is also a need to improve the learning and teaching facilities for inclusive schools as teachers and learners bemoan lack of teaching and learning materials suitable for hearing impaired learners. Teachers would be able to overcome some of the barriers to participation and learning which arise due to inadequate teaching and learning resources. Further research should be carried out to check people's understanding of the agenda of inclusive schools.
\end{abstract}

KEY WORDS: hearing impairment, hearing impaired learner, inclusion, exclusion

\subsection{Introduction}

Malawi places learners with hearing impairment in main stream schools rather than special schools as it was the trend in the past. Such a move is advocated for at an international level because it is seen as an equal opportunity issue which allows acceptance and inclusion of all learners. However, some people oppose the integration aspect because they argue that inclusion leads to exclusion (Jarvis 2002). According to Jarvis (2002), those who support integration of all learners into main stream schools neglect the fact that learners with hearing impairment have various educational, social and emotional needs which may not be resolved through integration. Supporters of the concept of inclusion also neglect the fact that hearing impaired learners need to develop their ability to function effectively not only in classrooms but in society as a whole. Additionally, some scholars bemoan the quality of education offered to learners in mainstream classrooms (see Ainscow, Dyson \& Weiner 2014). Integration of learners into main stream schools therefore falls short of fulfilling the main aim of inclusion which is offering quality education for all.

The aspect of education for all is not effectively being implemented especially in most African countries despite the existence of policies and legal framework that advocate for it. The learners who are integrated into main stream schools remain at a disadvantage because of several hindrances to effective learning. Muiti (2010) highlights some of the hindrances as follows: some buildings and structures that exist in schools are not adapted to accommodate individuals with disabilities. In addition, there is lack of mutual acceptance by people with disabilities and those without disabilities. For instance, Muiti (2010) explains that there is evidence based on her study that some hearing learners do not like attending classes 
together with hearing impaired learners and vice versa. Furthermore, some parents are not willing to have special needs children learning together with those without disabilities. In addition, most schools in African countries bemoan shortage of appropriate equipment and materials. Other hindrances that Muiti (2010) considers are general atmosphere at home; cleanliness and order of security; discipline and possession of books and papers that are not conducive to inclusive learners; and lack of competence by teachers and other personnel in as far as inclusive education classes are concerned.

However, besides the hindrances, inclusive education is beneficial to children with special needs in several ways (Raschke \& Bronson 1999). Firstly, it provides a diverse stimulating environment in which children with special needs grow and learn. Secondly, it brings the feeling to special needs children that they are part of a diverse community. Thirdly, it gives special needs children an opportunity to be educated with same age peers with diverse backgrounds. Inclusive education therefore enables a learner to experience diversity of a society on a small scale right in a classroom. Fourthly, it helps a learner to develop a sense of appreciation of the unique characteristics that each individual person possesses. Finally, it equips learners with socialisation as well as collaborative skills and as a result it builds supportiveness and interdependence.

\subsection{Statement of the problem}

In most African countries, it is a challenge for hearing impaired learners to learn effectively in both primary and secondary schools. This is attributed to the fact that learners do not have adequate learning resources to help them understand a lesson. Besides this, the impairment itself makes learners to be disadvantaged because of communication barriers. As a result, hearing impaired learners are excluded from the communication that goes on in inclusive classrooms - a sign that such classrooms fall short of being inclusive. Huge work load also makes teaching such learners even more difficult. Moreover, teachers are not trained to teach classes that include learners with hearing impairment. As a result, the academic performance of learners with hearing impairment is affected.

Several studies have been conducted regarding hindrances to effective teaching and learning of pupils with hearing impairment (see Jarvis 2002; Mpofu \& Chimhenga 2013; Muiti 2010). However, most of these studies have been carried out in African countries such as Tanzania and Kenya. In addition, the studies have focused on challenges faced when teaching and learning in general without explicitly looking at a specific subject. This study is therefore unique because it examines critical needs of hearing impaired learners during an English reading comprehension lesson.

\subsection{Purpose of the study}

The main purpose of this study was to examine critical needs of hearing impaired learners during an English reading comprehension lesson with a focus on some selected schools in the northern region of Malawi. This study was guided by the following specific objectives:

(i) To find out whether or not learners with hearing impairment are able to achieve reading comprehension objectives;

(ii) To analyse text comprehension strategies that teachers use during an English reading comprehension lesson; and

(iii) To identify challenges that learners encounter during an English reading comprehension lesson.

\subsection{Theoretical framework}

This study uses the social inclusion theoretical model. Scholars (see Reid-Cunningham \& Fleming 2009) use theoretical models from different disciplines of social sciences to understand disability issues because disability is naturally a social issue. The social inclusion model is one such theoretical model. This model is appropriate as it guides people's understanding of the critical needs of hearing impaired learners. The concept of social inclusion is basically discussed alongside social exclusion because the two terms are intertwined. According to Rawal (2008), social exclusion/inclusion as a concept became popular in France in the mid-1970s. Thereafter, it was adopted by the European Union in the late 1980s because it was regarded as a key concept in as far as social policy issues were concerned. The social inclusion/ 
exclusion concept actually replaced the poverty concept in many instances (Rawal 2008).

As pointed out earlier on, inclusion and exclusion are related concepts. Kearney and Kane (2006) regard inclusion and exclusion as two sides of the same coin because understanding one of the concepts requires an understanding of the other. De Haan (1998) defines social exclusion as the processes or the means by which people are excluded from participating in certain activities. Some individuals, institutions or organisations are seen to facilitate or hinder participation of some vulnerable groups in daily activities. Vulnerable groups include the following: "mentally and physically handicapped, suicidal people, aged invalids, abused children, substance abusers, delinquents, single parents, multi-problem households, marginal, asocial persons, and other social "misfits"' (Rawal 2008:162).

Another definition of social exclusion comes from Booth (1998). He states that exclusion is like segregation because it is the "process of decreasing the participation of pupils in the cultures and curricula of mainstream schools" (Booth 1998:34). This definition is relevant because it pinpoints the sort of exclusion that is typical in school environment, that is, from exclusion within school (such as being denied access to curriculum) to exclusion from school (such as being denied enrolment, suspension or expulsion). Students can be excluded by way of exclusion from the school curriculum, from social interactions and group membership, and from social rewards while still remaining in the school environment.

Social inclusion, on the other hand, is defined as a "means of enabling people with disabilities to do those ordinary things, make use of mainstream services and be fully included in the local community" (Bigby \& Frawley 2010:181). There are three elements that can be highlighted from the definition and other similar definitions that scholars provide as follows: issues of activity, participation and accessibility (Gates, 2007). Learners with disabilities should be able to participate in activities and access mainstream services. They should be provided with the much needed support and social services. Learners with disabilities need to have a sense of belonging as they are entitled to be treated equally as explained by Hall, Collins, Benjamin, Nind and Sheehy (2004:801) who regard inclusion as "a matter of entitlement, an issue of belonging within an educational community on equal terms".

The concept of social inclusion/exclusion was coined to resolve the challenges that vulnerable groups were experiencing; it was a response to the crisis of the welfare issues (Rawal 2008). Today the concept continues to be embraced with a similar agenda as its proponents strive to find ways to enable vulnerable groups to participate in activities impartially. Furthermore, they fight hard to ensure that people with disabilities not only make use of mainstream services but also become included in the local community. However, vulnerable groups do not enjoy full participation in activities. This is normally the case due to several factors as outlined by Ainscow, Dyson and Weiner (2014) such as: lack of a clear understanding of the agenda of inclusive schools; failure to overcome barriers to participation and learning because of inadequate human resources; failure to develop and utilise more inclusive practices in a classroom and lack of additional support for individual students because human resources that are available are not adequately trained.

It is important for people to have a clear understanding of inclusive education. Stainback, Stainback and Ayres (1996:36) consider inclusive schools as "places where everyone belongs, is accepted, and supports and is supported by his or her peers and other members of the school community in the course of having his or her educational needs met". Students who attend inclusive schools have rights like every other student to access the curriculum as a full-time member. Inclusive schools should therefore be a platform which embraces issues of activity, participation and accessibility.

\subsection{Literature review}

In this section, three different categories of studies are reviewed: studies which focused on reading comprehension skills of hearing impaired learners; studies which examined strategies that could be used with hearing impaired learners in order to increase their literacy skills and finally studies which analysed challenges that teachers face when teaching learners with hearing impairment. 


\subsection{Reading comprehension skills of hearing impaired learners}

There are some factors that play an important role in the comprehension skills of hearing impaired learners. These factors include vocabulary knowledge, phonology, mode of acquisition, and syntactic knowledge. However, our focus in this section is on two factors: vocabulary and phonology because, according to Bickham (2015), these two factors are regarded as the main sources of difficulty for hearing impaired learners. Bickham (2015:19) explains that "[in] regards to their reading comprehension abilities, vocabulary and phonology tend to be two areas that contribute to the lack of comprehension when students who are deaf or hard of hearing are reading".

Unlike hearing children, hearing impaired children do not have opportunities to acquire vocabulary and syntax from an early age (Mpofu \& Chimhenga, 2013). The loss of hearing prevents them from being exposed to oral language when they are infants. It is from this oral language where they would have gained more knowledge about vocabulary and syntax. However, such lack of exposure makes their understanding of some words and sentences used in comprehension passage even harder.

Research findings reveal that hearing impaired learners do not only have limited vocabularies (Luckner \& Cooke 2010) but they also perform poorly in tests on vocabulary knowledge compared to their hearing counterparts (Convertino, Borgna, Marschark \& Durkin 2014). In a particular way, Dockery's (2013) findings from reading comprehension levels of grade 4 to 12 Jamaican hearing impaired learners reveal that receptive vocabulary knowledge is one of the important predictors of reading comprehension. His study demonstrates an important strong correlation between vocabulary knowledge and reading comprehension.

Another study by Kunisue et al. (2007) demonstrates the effect that vocabulary knowledge has not only on the reading comprehension of hearing impaired learners but also on the development of their academic language skills. Kunisue et al. (2007:1672) argue that "[t]he ability to comprehend abstract words and ideas are essential in the development of academic language skills for hearing impaired children". Abstract words and ideas pose as a challenge to reading comprehension not only to hearing impaired learners but to hearing learners as well. It is therefore essential that both hearing and hearing impaired learners acquire such vocabulary "[b]ecause the acquisition of this abstract vocabulary plays an important role in development of their learning skills" (Kunisue et al. 2007:1672). Additionally, hearing impaired learners need to be exposed to figurative language such as idioms and proverbs because in most cases figurative language knowledge of hearing impaired children is much poorer than that of hearing children (Giang \& Inho 2014). Overall, hearing impaired participants are less competent in detecting the correct meanings of sentences than their hearing counterparts (Kelly \& Berent 2011); hence the need to look into vocabulary factors to enhance the reading comprehension skills of hearing impaired learners.

Regarding phonology, even though some studies report conflicting results (Colin et al. 2013; Daza et al. 2014), there is overwhelming evidence about a positive connection between phonological skills and reading comprehension (Allen et al. 2009; Wang et al. 2008). According to Allen et al. (2009), phonological awareness and phonological decoding have an impact on reading comprehension as these skills enhance the lexical processing of written words.

\subsection{Text comprehension strategies for hearing impaired learners}

The National Reading Panel (NRP) in the United States recommends the following as effective strategies to reading comprehension: comprehension monitoring, cooperative learning, graphic and semantic organisers, question answering, question generation, and summarisation (Benedict, Rivera \& Antia 2015). According to Benedict et al. (2015), instruction that capitalises on a combination of strategies makes reading comprehension more effective than instruction that solely relies on a single strategy. Other scholars such as Schirmer and McGough (2005) recommend the use of story structure and question answering as effective strategies for improving reading comprehension for deaf and hard of hearing students. On the other hand, Benedict et al. (2015) argue that providing instruction using higher-order cognitive thinking skills such as activating prior knowledge, making predictions, drawing inferences, and summarising improves students' reading comprehension. Some of the effective strategies that could be used prior to reading, during reading and after reading, according to McAnally and Rose (1999); and Rose, McAnally and Quigley (2003), are summarised in Table 1. 
Table 1: Strategies that are used prior to reading, during reading and after reading

\begin{tabular}{|c|c|c|}
\hline Strategies Prior To Reading & Strategies During Reading & Strategies After Reading \\
\hline $\begin{array}{l}\text { Pre-teaching/pre-learning vocabulary and } \\
\text { grammar }\end{array}$ & Making inferences & $\begin{array}{l}\text { Deciding if you have achieved } \\
\text { your goal for reading }\end{array}$ \\
\hline Activating prior knowledge & $\begin{array}{l}\text { Relating what you are reading to } \\
\text { what you already know }\end{array}$ & Retelling \\
\hline Understanding your purpose for reading & $\begin{array}{l}\text { Asking questions that will need } \\
\text { to be answered }\end{array}$ & $\begin{array}{l}\text { Using self-evaluation of } \\
\text { comprehension }\end{array}$ \\
\hline $\begin{array}{l}\text { Asking any questions printed at the end of } \\
\text { the chapter, if applicable }\end{array}$ & $\begin{array}{l}\text { Activating mental imagery } \\
\text { based on prior knowledge, } \\
\text { visual cues, and information } \\
\text { accumulated from the text. }\end{array}$ & $\begin{array}{l}\text { Summarising main ideas and } \\
\text { important points }\end{array}$ \\
\hline $\begin{array}{l}\text { Observing, reviewing, discussing pictures, } \\
\text { titles, captions, etc. to aid in comprehension }\end{array}$ & Using summarisation skills & $\begin{array}{l}\text { Thinking about what made your } \\
\text { prediction good or bad }\end{array}$ \\
\hline $\begin{array}{l}\text { Using summarisation skills (what do you } \\
\text { think the story is going to be "about") }\end{array}$ & $\begin{array}{l}\text { Using self-monitoring of } \\
\text { comprehension (clarifying } \\
\text { misunderstandings) }\end{array}$ & $\begin{array}{l}\text { Relating what you read to your } \\
\text { real life }\end{array}$ \\
\hline
\end{tabular}

\subsection{Challenges experienced by hearing impaired learners}

Some of the challenges that hearing impaired learners encounter are language related which include language use, vocabulary development, speaking, academic achievement and social functioning (Mpofu \& Chimhenga 2013). Mpofu and Chimhenga's findings reveal that most hearing impaired learners have difficulties in expressing themselves. In addition, they find it difficult to develop English language vocabulary because they hardly hear when other people are communicating. According to Mpofu and Chimhenga, hearing impaired learners also have problems with speaking in terms of pitch, volume, stress and rate of their speech.

Furthermore, hearing impaired learners have problems related to their academic achievement, especially reading and mathematical concepts (Mpofu \& Chimhenga 2013). They also feel isolated and unhappy in school especially when their socialisation with other children with hearing loss is limited. Other challenges are summarised as follows: lack of proper syllabus, inadequate teaching and learning facilities, lack of in service training for the teachers of special education and also lack of information to facilitate their learning (Mtuli 2015). According to Muiti's (2010) findings, challenges can be ranked in terms of most to least worrisome. Muiti considers difficulty in explaining abstract concepts as one of the biggest challenges while regular absenteeism the least worrisome. Ranking challenges in this order is helpful because people will know which challenges require immediate attention and which ones do not. However, the ranking may not be constant as the challenges may be viewed differently by different societies.

\subsection{Methodology}

The focus in this section is on the following: research design that guided this study, geographical area of the study, sample population, sampling technique and sample size, information about data collection techniques, data analysis and ethical consideration.

\subsection{Research design}

This study used a qualitative research design. Several scholars (Bailey, Hennink \& Hutter 2011; Brink \& Wood 1998; Kothari 1985; Kumar 2005) support the use of the qualitative research design for numerous reasons. According to Bailey, Hennink and Hutter (2011), qualitative research allows the researcher to examine people's experience in detail. It also enables the researcher to understand social problems from multiple perspectives. It further assists the researcher to collect rich data on real life situations 
concerning people. Finally, qualitative research enables the researcher to collect data that can be coded and categorised into themes.

\subsection{Geographical area of the study}

Data for this study was collected from three secondary schools that are located in Mzuzu city and Mzimba district in the northern region of Malawi as follows: Nkhorongo Community Day Secondary School (CDSS), Luwinga Secondary School (SS) and Mzimba Secondary School (SS). The three schools are representative of the categories of the secondary schools that exist in Malawi; Nkhorongo and Luwinga represent community and district day secondary schools respectively while Mzimba is a district boarding school. Furthermore, the schools are located in the region where the researcher is based; this therefore enabled the researcher to do semi-structured and follow-up interviews with much ease.

\subsection{Sample population, sampling technique and sample size}

The following categories of participants were the target in this study: regular teachers who teach English subject to hearing impaired learners, resource persons, specialist teachers in humanities subjects and hearing impaired learners. Purposive sampling was therefore used to find the desired participants. A total of twenty-six participants from three secondary schools participated in this study as follows: three regular teachers from Nkhorongo CDSS, two regular teachers and two specialist teachers from Luwinga SS, two regular teachers and two resource persons from Mzimba SS and five hearing impaired learners from each of the schools. The researcher targeted twenty-six participants in order to effectively conduct in-depth interviews. Furthermore, since the participants hold different positions at the schools, they would provide insights regarding critical needs of hearing impaired learners.

\subsection{Data collection techniques}

Semi-structured interviews were used in order to collect data from the selected participants. In some cases, follow-up interviews were conducted to seek clarification on certain responses. The purpose of this study and the specific objectives formed the basis for the interview questions. All the interviews were audio recorded in order to maintain the original data. Audio recordings are crucial because they provide a complete verbal record which can be studied much more thoroughly (Gall, Gall \& Borg 2007).

\subsection{Data analysis}

All the audio recordings were transcribed. After transcribing the recordings, thematic analysis was used to organise the data. According to Braun and Clarke (2013), thematic analysis considers the following six basic steps: familiarising with the data through thorough reading of the transcribed data, generation of initial codes, searching for themes, reviewing the themes, defining and naming themes that are developed and producing the report.

\subsection{Ethical consideration}

All the participants were informed about the purpose of the study. They were also briefed that their participation in this study was voluntary. The participants were assured that their views and opinions would be treated with maximum confidentiality and that they would be used anonymously. The participants were also assured that the study findings would only be used for academic purposes only.

\subsection{Results and discussion}

This section presents and discusses the findings of this study. The content in this section is organised and presented in accordance with the themes corresponding to each of the specific objectives. 


\subsection{Whether or not students with hearing impairment are able to achieve reading comprehension objectives}

Firstly, the results reveal that most hearing impaired learners manage to predict content of written text from a title. However, they manage to answer comprehension questions after reading a passage repetitively. The findings reveal that hearing impaired learners struggle to do the following: identify key words that signal central idea, define or explain key words that signal central idea, identify central idea from the title of the written text and explain central idea. The results further reveal that hearing impaired learners complain that they are not given enough time to understand comprehension passages. They also complain that vocabulary from comprehension passages is usually difficult. If students complain about inadequate time and difficulty vocabulary, then tasks such as identifying key words that signal central idea, defining or explaining key words as well as explaining central ideas would be challenging.

Furthermore, inadequate time and difficulty vocabulary entail that inclusive classes in which these hearing impaired learners learn fall short of being inclusive because according to the teachers it is only hearing impaired learners who present such complaints. A typical inclusive class would fully utilise resource persons to provide interpretation and other services to hearing impaired learners. A typical inclusive class would also provide reading passages to hearing impaired learners in advance before the set lesson. Unfortunately, only one out of the three schools that were sampled in this study had resource persons who would provide sign language services to hearing impaired learners. Inclusive education classes require resource persons to complement the services offered by teachers.

The results in this study are supported by what Mpofu and Chimhenga (2013) found. Their results reveal that hearing impaired learners struggle to develop English vocabulary because of their inability to hear when other people are communicating. Mtuli (2015) also reports that hearing impaired learners do not have normal language abilities and as a result they find it hard to communicate in inclusive education classes which do not capitalise on the use of sign language.

Similarly, Bickham's (2015) findings indicate that vocabulary is one of the main sources of difficulty for hearing impaired learners in as far as reading comprehension is concerned. Bickham's explanations reveal that vocabulary challenges are attributed to the fact that hearing impaired learners do not have opportunities to acquire vocabulary as well as syntax from an early age (see Mpofu \& Chimhenga, 2013). Additionally, Dockery's (2013) findings also reveal an important strong correlation between vocabulary knowledge and reading comprehension. According to Aceti and Wang (2010), majority of vocabulary deficiency in hearing impaired learners is as a result of their limited access to multi-meaning words. Aceti and Wang (2010) stress the importance for teachers to facilitate the acquisition of not only ordinary vocabulary but also abstract, multi-meaning words and figurative language by both hearing and hearing impaired learners because the acquisition of such vocabulary, in accordance with Kunisue et al.'s (2007) findings, plays an important role in development of their learning skills.

Difficulties in vocabulary eventually lead to poor performance in English and other subjects. It is reported by Mpofu and Chimhenga (2013) that students with hearing impairment have difficulty with all areas of academic achievement, especially reading and mathematical concepts. They also report that the gap in academic achievement between children with normal hearing and those with hearing impairment usually widens as they progress through school. The question worth asking is why would the situation worsen instead of improving when students progress to other classes? Such retrogressive achievements could be a sign that the affairs of hearing impaired learners are not attended to. In other words, inclusive education classrooms might barely be inclusive.

Teachers in inclusive schools should consider the following in order to enhance the inclusivity during their lessons. Firstly, they need to encourage their learners to read widely. Secondly, they need to find alternative ways of explaining abstract concepts to their learners. Mpofu and Chimhenga (2013) suggest that abstract concepts can be explained by rephrasing them with additional words relevant to the concept being explained. Thirdly, teachers should use the strategy of rephrasing sentences; this may enrich students' understanding of the comprehension lesson. Fourthly, teachers should provide relevant cues that aid comprehension (Mpofu \& Chimhenga 2013). Fifthly, teachers need to rework their teaching methodology for learners with some needs. Innovation and embracing technology in teaching also needs 
to be championed. Technology must be inclusive so that it is does not exclude any learner. Sixthly, teachers should frequently check hearing impaired learners to see whether or not they are following the lesson. If they are not, other strategies may be used to enhance their understanding. For instance, the teacher can repeat questions and comments uttered by other students in class who may not be in the range of vision of the hearing impaired learner. Repeating what is said is viewed as one of the important solutions in cases where students do not understand certain concepts during a lesson. Finally, teachers should be patient and committed to their duty because an impatient and frustrated teacher who is only teaching to pass time and wait for monthly salary is a danger to the impaired learners. In this regard, teaching ethics need to be strengthened, especially among teachers who handle impaired learners.

\subsection{Text comprehension strategies that are used when teaching reading comprehension}

The results reveal that teachers from the three schools believe that the use of general teaching, learning and assessment methods assist students to achieve reading comprehension objectives. They stressed that the use of a variety of methods is helpful because when a student has a problem in understanding central ideas from a passage during individual work, the ideas would be understood when another method such as group work is used. Ideas that were not initially understood would therefore be clarified during group work. Table 2 summarises the strategies that teachers from the three schools use.

\section{Table 2: Strategies that teachers use when teaching reading comprehension}

\begin{tabular}{|l|l|l|}
\hline Nkhorongo CDSS & Luwinga SS & Mzimba SS \\
\hline Pre-reading activities & $\begin{array}{l}\text { Group work, pair work, explanation, } \\
\text { whole class discussion, individual } \\
\text { work, demonstration and use of } \\
\text { gestures }\end{array}$ & $\begin{array}{l}\text { The use of textbooks and a variety } \\
\text { of passages for comprehension } \\
\text { exercises }\end{array}$ \\
\hline $\begin{array}{l}\text { Frequent exercises that enhance their } \\
\text { reading comprehension skills }\end{array}$ & Silent reading and individual reading & $\begin{array}{l}\text { Repetition and reading a passage } \\
\text { several times, writing new words } \\
\text { on the board and providing their } \\
\text { meanings where necessary }\end{array}$ \\
\hline $\begin{array}{l}\text { Assigning group members to be } \\
\text { assisting hearing impaired learners }\end{array}$ & & \\
\hline Predictions from titles or pictures & & \\
\hline Skimming and scanning & & \\
\hline
\end{tabular}

The teachers do not only rely on one strategy but a combination of strategies as stipulated by Benedict et al. (2015:5) that "instruction that emphasizes purposefully selecting and combining multiple strategies, is more effective than instruction that emphasizes using any one strategy alone". The importance of using several strategies has been stressed by Schirmer and McGough (2005) who single out the use of story structure and question answering as being effective for improving reading comprehension for deaf and hard of hearing students. In Malawi, the use of story structure is part of the national reading programme being implemented in primary schools. There is currently an innovation programme called 'story star' in which grade six learners are taught comprehension skills through the use of story structure. The 'story star' strategy may also be applicable to students at secondary school level and it could be more beneficial to hearing impaired learners.

However, some strategies that are found to be useful by some scholars were not mentioned by the teachers and hearing impaired learners in this study. These strategies include the use of graphic and semantic organisers, question generation and inferencing (Benedict et al. 2015). The teachers who participated in this study indicated that they ask students questions after reading a passage but they do not encourage them to generate their own questions from assigned passages and neither do they tell them to use graphic and semantic organisers. Graphic and semantic organisers are useful for presenting meanings of difficult vocabulary as well as outlines of main ideas from assigned passages. The learners also revealed 
that teachers do not encourage them to make inferences as they only capitalise on explicit questions. Furthermore, it is worth noting from the strategies in Table 2 that technology is not yet fully embraced. Technology is one area that can solve several problems that hearing impaired learners encounter. There is therefore need to invest in technology to make it accessible to every learner so that it is not just a privilege to few people.

\subsection{Challenges which hearing impaired learners encounter during an English reading comprehension lesson}

Firstly, hearing impaired participants revealed that they have difficulties in understanding most of the verbal instructions used in class because the teachers are not trained to teach learners with hearing impairment. The teachers admitted their lack of skills in teaching hearing impaired learners but they indicated that they try hard to use a combination of verbal and written communication through the use of chalk boards or chart papers. The results of this study are similar to what Mtuli (2015) found in Tanzania to the extent that she bemoaned the lack of in service training for inclusive education teachers. If teachers are properly trained, they would be able to teach inclusive classes effectively.

The results also reveal that there is lack of teaching and learning materials suitable for hearing impaired learners. In addition, hearing impaired learners do not use hearing aids and other technological gadgets that other countries, especially in Europe, utilise. The problem of lack of resources appears to be common in most African countries. Mtuli (2015), Muiti (2010) and Udoba (2014) who conducted their studies in Tanzania and Kenya report similar findings. It is an outcry for many teachers to have more advanced teaching materials such as audio and TV for teaching (Udoba, 2014). Other teaching and learning materials include visual media especially overhead projectors or PowerPoint (Mpofu \& Chimhenga 2013). According to Mpofu and Chimhenga, these are effective tools because they enhance the learning process for the hearing impaired learners.

It is the wish of most teachers and learners to have governmental and non-governmental organisations that could help in purchasing all the required teaching and learning materials. According to Udoba (2014), most teachers would like to be using modern teaching and learning materials as opposed to the locally available materials because the latter do not motivate learning. Udoba also points out that teachers may not be able to utilise appropriate teaching methods and approaches when modern teaching and learning materials are not available. However, teachers should be seen to be resourceful when modern teaching and learning materials are lacking. Teachers should supplement what is available through photocopying of passages from text books, newspapers and other sources. In agreement, Mpofu and Chimhenga (2013) state that teachers can enhance the learning process and communication using the following: pictures, illustrations, artefacts, slides, computer graphics, films with captions, charts and the internet.

Other challenges that hearing impaired participants revealed in this study include failure to lip read correctly and inability to get what is uttered when sitting in a position far away from the teacher. The learners further revealed that lip reading needs to be accompanied by facial expressions so that they do not misinterpret communication from the teacher. Lip movement may indeed be misleading especially when producing similar words such as 'man' and 'mad'. In view of this, the teacher participants stressed the importance of using appropriate facial expressions and pronunciations. Some of the solutions to these challenges, according to Mpofu and Chimhenga (2013), include making hearing impaired learners sit closer to the teacher such as the front row so that they can lip read easily. Mpofu and Chimhenga also point out that lip reading would be made simple if teachers face hearing impaired learners during all oral communication. Additionally, Mpofu and Chimhenga (2013) advise teachers to make sure that hearing impaired learners do not have unobstructed view of the teacher. Any obstruction may prevent the students from lip reading what the teacher says throughout the lesson. Besides, Mpofu and Chimhenga (2013) stress the importance of having classrooms that have good lighting so that visual aids can be clearly seen. They argue that visual information should be used to reinforce auditory information.

Furthermore, some hearing impaired learners revealed that they are not happy with their performance in English. In response, the teachers said that the low performance is attributed to learners' challenges in developing English vocabulary since they hardly hear when other people are communicating. As a result, 
this affects their performance in tasks that assess their ability to understand a comprehension passage. It is a requirement for secondary school students in Malawi to know how to summarise a passage because the national examinations in the final year of secondary school assess them in this area. However, writing summaries is considered as one of the difficult tasks for hearing impaired learners according to the responses from the learners and teachers. This is evidenced by the low scores that they get from such tasks. One of the teachers said the following:

\section{Hearing impaired learners produce long summaries that exceed the required number of words.}

Furthermore, another teacher stated that hearing impaired learners are slow in giving out responses to oral tasks. This therefore contributes to their low participation in class and poor results. In addition, other attributes of hearing impaired learners appear to contribute to their low participation as pointed out by one of the teachers as follows:

They always feel inferior and shy. However, they need to be courageous to explore more about their subjects as there is one deaf student who is very good at Maths and other hearing impaired learners managed to obtain good grades in English examinations written in the past years.

It is important to point out that teachers have a role to play to facilitate meaningful and effective participation of hearing impaired learners in classroom activities. They need to find ways to encourage and motivate hearing impaired learners. Otherwise, failure to do so exacerbate hearing impaired learners' exclusion.

Another challenge contributing to their low participation in classroom activities, according to one of the hearing impaired learners, is distractions during group work. Distractions make it difficult for them to focus on given tasks. The learner particularly stressed that any movement or noise within their environment easily makes them lose their concentration. Furthermore, distractions make them miss teachers' instructions. In response to these challenges, one of the teachers stressed the importance of making the classrooms conducive to learning. He explained that if there is noise within or outside the classroom, teachers instruct students to minimise the noise. This normally happens when doing group work and other activities that are distractive. Even though the teacher responded in this manner, the learners expressed dissatisfaction that the assistance they get from the teachers is sometimes not enough to the extent that they occasionally turn to their classmates for further assistance especially when they miss instructions because of noise. However, sometimes their classmates do not always come to their rescue as revealed by one of the learners in the following excerpt:

Hearing students do not always help us when we ask them about certain points that we did not clearly understand in class. Hearing students usually think that we ask obvious questions. I feel hearing students should be assisting us when we are in need.

In view of the above excerpt, it is important for teachers to use every opportunity to teach other students about hearing loss and what could be done to support hearing impaired learners in class (Mpofu \& Chimhenga 2013). There is also a need for parents and other relations to be supportive. For instance, they can help hearing impaired learners with further clarifications. However, this may be possible if the students have parents and relations who are educated. This also works well when teachers inform parents in advance on what is covered in class so that parents can source the necessary supplementary materials. According to Mpofu and Chimhenga (2013), there is a need for teachers to give students in advance a brief course outline, a syllabus, and a list of learning objectives. They explain that these could be distributed to learners at the beginning of the term so that they can be helped at home by parents and other relations. They therefore stress the importance of collaboration between teachers and parents. Collaboration with parents is crucial because parents know the needs of their children better than teachers. According to 
Udoba (2014:62), "[p]arents know their children better; they know their educational needs, their interests and what is good for them, therefore, they can plan for the future on behalf of their children".

The results of this study make one wonder why the learners feel free to consult fellow learners for further clarifications instead of consulting their teachers. One would also wonder why assistance from fellow learners is hard to get. Furthermore, one would be compelled to ask questions such as, 'are these classes inclusive enough?' An environment such as this one where a learner is not free to ask questions, in Vygotsky's (1978) views, is not a suitable environment for a child with a disability. Vygotsky supports the type of education in which entire staff, fellow learners, members of the community, and so on, are able to exclusively serve the needs of individuals with a disability.

It appears that the classroom environment for the learners interviewed in this study does not capitalise on the three elements of inclusion (that is, issues of activity, participation and accessibility) highlighted by Gates (2007). As revealed by the findings of this study, hearing impaired learners do not participate fully in activities nor do they access mainstream services. Furthermore, they are not provided with the much needed support and services as expected in an inclusive classroom and the aspect of inclusion is lacking because not all learners participate in the learning (Hall et al. 2004).

Having reached this far, it is important to point out that an inclusive class is not a class without shortcomings. However, teachers and relevant authorities need to strive to overcome them as much as they can. Above all, teachers and relevant authorities need to work hard to achieve the much needed inclusivity. In other words, they need to do their utmost best so that hearing impaired learners are not affected to a great extent.

\subsection{Conclusion and implications}

The results have revealed that most hearing impaired learners do not manage to achieve all reading comprehension objectives. The results have also revealed that teachers manage to use a combination of strategies during a reading comprehension lesson. However, some strategies that are found to be useful by some scholars were not mentioned by the teachers and hearing impaired learners in this study. Such strategies include the use of graphic and semantic organisers, question generation and inferencing (Benedict et al. 2015). These strategies are useful because they promote higher-order cognitive thinking skills. Finally, the results have revealed that hearing impaired learners encounter several challenges some of which may be avoided if teachers embrace inclusive practices.

This study has implications for stakeholders (for instance, ministry of education and non-governmental organisations), teachers and researchers. Firstly, since the results have revealed that some teachers are not skilled to teach hearing impaired learners, there is a need for in-service training for teachers of hearing impaired learners in order to increase competency in sign language so that they can make use of total communication during instruction. There is also a need to improve inclusive system of education by employing competent specialist teachers and resource persons in both subject matter and sign language in order to improve the learning of hearing impaired learners. Competent specialist teachers and resource persons will help to develop and utilise more inclusive practices in a classroom.

School officials need to find ways of motivating hearing impaired teachers because they are required to use extra time to repeat lessons or clarify content for hearing impaired learners. In this way, the performance of hearing impaired learners may improve. The ministry of education also needs to intervene by increasing learning and teaching facilities for those inclusive schools in order to improve the teaching and learning of hearing impaired learners. Teachers sometimes fail to overcome some of the barriers to participation and learning because of inadequate teaching and learning resources.

There should be further research in order to check people's understanding of the agenda of inclusive schools. If understanding is lacking, the ministry of education may intervene with awareness programmes. Such awareness programmes may target teachers, resource persons, school officials as well as members of the community. Involving members of the community is crucial because hearing impaired learners need additional support from various stakeholders. 


\section{References}

Aceti, K. \& Wang, Y. (2010). 'The teaching and learning of multimeaning words within a metacognitively based curriculum', American Annals of the Deaf, 155(2), 118-123.

Ainscow, M., Dyson, A. \& Weiner, S. (2014). 'From exclusion to inclusion: A review of international literature on ways of responding to students with special educational needs in schools', En-clave Pedagógica, 13, 13-30.

Allen, T. E., Clark, M. D., Giudice, A. D., Koo, D., Lieberman, A., Mayberry, R. \& Paul, M. (2009). 'Phonology and reading: A response to Wang, Trezek, Luckner, and Paul', American Annals of the Deaf, 154 (4), 338-345.

Bailey, A., Hennink, M. \& Hutter, I. (2011). Qualitative research methods, SAGE Publication, Inc., London.

Benedict, K. M., Rivera, M. C. \& Antia, S. D. (2015). 'Instruction in metacognitive strategies to increase deaf and hard of hearing students' reading comprehension', Journal of Deaf Studies and Deaf Education, 20(1), 1-15.

Bickham, L. M. (2015). 'Reading comprehension in deaf education: Comprehension strategies to support students who are deaf or hard of hearing', Master's Thesis, St. John Fisher College, United States of America.

Bigby, C. \& Frawley, P. (2010). Social work practice and intellectual disability, Palgrave Macmillan, New York.

Booth, T. (1998). 'Stories of exclusion: Natural and unnatural selection', in E. Blyth \& J. Milner (eds), Exclusion from School: Inter-professional issues for policy and practice, pp. 21-36, Routledge, London.

Braun, V. \& Clarke, V. (2013). Successful qualitative research: A practical guide for beginners, Sage, London.

Brink, P. \& Wood, M. (1998). Advanced designs in nursing research (2nd Ed.), Sage, Thousand Oaks.

Colin, S., Leybaert, J., Ecalle, J. \& Magnan, A. (2013). 'The development of word recognition, sentence comprehension, word spelling, and vocabulary in children with deafness: A longitudinal Study', Research in Developmental Disabilities, 34, 1781-1793.

Convertino, C. M., Borgna, G., Marschark, M. \& Durkin, A. (2014). 'Word and world knowledge among deaf students with and without cochlear implants', Journal of Deaf Studies and Deaf Education, 19, 471-483. Doi: 10.1093/deafed/enu024.

Daza, M., Philips-Silver, J., Ruiz-Cuadra, M. \& Lopez-Lopez, F. (2014). 'Language skills and nonverbal cognitive processes associated with reading comprehension in deaf children', Research in Developmental Disabilities, 35, 3526-3533.

De Haan, A. (1999). 'Social exclusion: An alternative concept for the study of deprivation?', IDS Bulletin, 29 (1), 10-19.

Dockery, K. F. (2013). 'The reading comprehension of deaf/hard-of-hearing Jamaican students: The contributions of intellectual ability, sign-language comprehension, vocabulary knowledge, and metacognitive awareness', Doctoral thesis, McGill University, Quebec, Canada. Retrieved July 20, 2019, from http://digitool.library.mcgill.ca/webclient/StreamGate?folder_ id $=0 \& d v s=1493211996296 \sim 309$.

Gall, M. D., Gall, J. P. \& Borg, W. R. (2007). Educational research: An introduction (8 ${ }^{\text {th }}$ ed.), Longman, New York.

Gates, B. (2007). Learning disabilities: Towards inclusion $\left(5^{\text {th }} \mathrm{ed}\right)$, Elsevier, London.

Giang, D. L. \& Inho, C. (2014). 'Comprehension of figurative language by hearing impaired children in special primary schools', Social and Behavioral Sciences, 191, 506-511.

Hall, K., Collins, J., Benjamin, S., Nind, M. \& Sheehy, K. (2004). 'SATurated models of pupildom: Assessment and inclusion/exclusion', British Educational Research Journal, 30(6), 801-817.

Jarvis, J. (2002). 'Exclusion by inclusion? Issues for deaf pupils and their mainstream teachers', Education 3-13, 30 (2), 47-51, DOI: 10.1080/03004270285200231. 
Kearney,A. \& Kane, R. (2006). 'Inclusive education policy in New Zealand: reality or ruse?', International Journal of Inclusive Education, 10 (2-3), 201-219.

Kelly, R. R. \& Berent, G. P. (2011). 'Semantic and pragmatic factors influencing deaf and hard of hearing students' comprehension of English sentences containing numeral quantifiers', Journal of Deaf Studies and Deaf Education, 16(4), 419-436.

Kothari, J. (1985). Research methodology: Methods and techniques, Wiley Eastern Limited, New Delhi. Kumar, R. (2005). Research methodology: A step-by-step guidefor beginners ( $2^{\text {nd }}$ ed.), Pearson Education, Singapore.

Kunisue, K., Fukushima, K., Kawasaki, A., Maeda, Y., Nagayasu, R., Kataoka, Y., Kariya, S., Fukutomi, Y., Takami, H. \& Nishizaki, K. (2007). 'Comprehension of abstract words among hearing impaired children', International Journal of Pediatric Otorhinolaryngology, 71, 1671-1979.

Luckner, J. \& Cooke, C. (2010). 'A summary of the vocabulary research with students who are deaf or hard of hearing', American Annals of the Deaf, 155(1), 38-67.

McAnally, P. \& Rose, S. (1999). Reading practices with deaf children, PRO-Ed., Austin, Texas.

Mpofu, J. \& Chimhenga, S. (2013). 'Challenges faced by hearing impaired pupils in learning: A case study of King George VI Memorial School', Journal of Research \& Method in Education, 2 (1), 69-74.

Mtuli, J. (2015). 'Assessing the challenges of teaching and learning of hearing impaired students enrolled in regular primary and secondary schools in Tanzania', Master's Thesis, Open University of Tanzania, Tanzania. Retrieved January 23, 2020, from http://repository.out.ac.tz/1429/1/Mtuli Tellah_Charles.pdf.

Muiti, M. J. (2010). 'Hindrances to effective learning of pupils with hearing impairment in Meru North District-Kenya', Master's Thesis, Kenyatta University, Kenya. Retrieved January 21, 2020, from http://ir-library.ku.ac.ke/bitstream/handle/123456789/620/Muiti,\%20Jennifer.pdf?...3.

Raschke, D. \& Bronson, J. (1999). 'Creative educators at work: All children including those with disabilities can play traditional classroom games'. Retrieved October 10, 2019, from http://www. cec.sped.org./bk - menu. htm.12.6.2007.

Rawal, N. (2008). 'Social inclusion and exclusion: A review', Dhaulagiri Journal of Sociology and Anthropology, 2, 161-180.

Reid-Cunningham, A. R. \& Fleming, V. C. (2009). 'Theories of disability: Findings from an analysis of textbooks on human behavior and the social environment', Journal of Human Behavior in the Social Environment, 19(1), 10-25, DOI: 10.1080/10911350802616181.

Rose, S., McAnally, P. L. \& Quigley, S. P. (2003). Language development practices with deaf children ( $3^{\text {rd }}$ ed.), PRO-Ed., Austin, Texas.

Schirmer, B. R. \& McGough, S. M. (2005). 'Teaching reading to children who are deaf: Do the conclusions of the National Reading Panel apply?', Review of Educational Research, 75(1), 83-117.

Stainback, S., Stainback, W. \& Ayres, B. (1996). 'Schools as inclusive communities', in W. Stainback \& S. Stainback (eds), Controversial issues confronting special education: Divergent perspectives (2nd Ed), pp. 31-43, Allyn \& Bacon, Boston, MA.

Udoba, H. A. (2014). 'Challenges faced by teachers when teaching learners with developmental disability', Master's Thesis, Open University of Oslo, Norwey. Retrieved January 27, 2016, from https://www. duo.uio.no/bitstream/handle/10852/42438/Master-thesis-Humphrey-2-2.pdf?sequence=1.

Vygotsky, L. (1978). Mind in society: The development of higher psychological processes, Harvard University Press, Cambridge.

Wang, Y., Trezek, B. J., Luckner, J. \& Paul, P. V. (2008). 'The role of phonology and phonologically related skills in reading instruction for students who are deaf or hard of hearing', American Annals of the Deaf, 153(4), 396-407. 